\title{
An unusual case of late hematoma after implant-based breast reconstruction mimicking an anaplastic large cell lymphoma: a case report and literature review
}

\author{
Paolo Fioramonti $^{1} \cdot$ Stefano Lovero ${ }^{1} \cdot$ Juste Kaciulyte ${ }^{1} \cdot$ Diego Ribuffo $^{1} \cdot$ Jacopo M. Frattaroli $^{1}$
}

Received: 24 November 2020 / Accepted: 14 January 2021 / Published online: 6 March 2021

(C) The Author(s) 2021

\begin{abstract}
Late hematoma associated with breast implants used in esthetic and reconstructive breast surgery represents a rare entity. These hematomas do not have a clear etiology, but triggering events like trauma, anticoagulant use, capsule contracture, or chronic inflammation are reported in literature. We describe an 82-year-old patient who developed a unilateral intra-capsular hematoma 19 years after mastectomy and breast reconstruction with McGhan $445 \mathrm{~g}$ implant. Differential diagnosis with anaplastic large cell lymphoma (ALCL) was considered and potential causes of hematoma were evaluated. Constant pressure forces on chest wall were defined as pathophysiological cause. A systematic literature review concerning late hematoma cases was carried out, focusing on late hematoma etiology and various surgical treatments.
\end{abstract}

Level of evidence: Level $\mathrm{V}$, diagnostic study.

Keywords Late hematoma $\cdot$ Anaplastic large cell lymphoma $\cdot$ Breast implants

\section{Introduction}

Early hematoma is a well-documented complication observed in $2-10.3 \%$ of patients who underwent implant breast surgery $[1,2]$. To date, peri-prosthetic late hematoma remains a very uncommon complication with increasing cases over last years in reconstructive and esthetic breast surgery. According to a recent review, [3] only 18 patients have reported late hematoma after reconstructive implant procedure and 31 after esthetic purpose with implants [4]. The most lasting breast implantation followed by explantation was reported in 2007 by Nahabedian [5], where the prosthesis removal was performed 41 years after its positioning, with late hematoma as the principle reason for surgery. Late hematomas do not have clear etiological mechanisms or specific symptoms, even if some authors [3] have suggested several triggering events like trauma, anticoagulant use, physical strain, post-chemotherapy

Stefano Lovero

stefano.lovero@uniroma1.it

1 Department of Surgery "P.Valdoni", Unit of Plastic and Reconstructive Surgery, Policlinico Umberto I, Sapienza University of Rome, Viale del Policlinico, 155 Rome, Italy immunodeficiency, or highly vascular inflammatory response for polyurethane-coated implants. However, a peri-prosthetic fluid effusion may represent the clinical manifestation of breast implant associated-anaplastic large cell lymphoma (BIA-ALCL) [6]. ALCL clinically presents as a delayed, persistent peri-prosthetic seroma with a consequent breast swelling and other nonspecific clinical signs [7, 8]. Therefore, it should be considered in the differential diagnosis of breast swelling. The estimated incidence of BIA-ALCL is 2.03 per 1 million person years with an estimated prevalence of 1 per 30,000 women with breast implants [9]. Exclusion diagnosis is confirmed by immuno-histological and cytological findings of peri-prosthetic fluid, because BIA-ALCL is characterized by abnormal CD30 positive and anaplastic lymphoma kinase (ALK) negative lymphocytes. Expression of other T cell antigens, e.g., CD4 (84\%), CD43 (80\%), CD3 (30\%), CD45 $(36 \%)$, and $\mathrm{CD} 2(30 \%)$, is variable $[10,11]$.

In this article, we present a unique clinical case of 82-yearold female patient who came to our unit for an abrupt monolateral breast swelling. Nineteen years before, she had undergone mastectomy and two-stage expander/prosthesis breast reconstruction. In this clinical case, imaging data of CT and MRI showed no certain signs of intra- or extracapsular implant rupture and could not discriminate a periprosthetic seroma from hematoma. Intraoperatively, a large 
late hematoma was found and an original etiological hypothesis was identified.

\section{Case report}

In January 2018, an 82-year-old woman came to first aid unit of Policlinico Umberto I Hospital for a non-surgical moderate pericardial effusion $(18 \mathrm{~mm})$. She presented a medical history of treated hypertension, left nephrectomy for renal tuberculosis (1972), treated chronic renal failure, and obstructive chronic bronchopathy (since 2009). In February 1999, she had developed a ductal infiltrating breast cancer and underwent a left radical skin-reducing mastectomy and axillary lymphadenectomy, followed by an immediate reconstruction with tissue expander, placed under pectoralis major and serratus anterior. Post-surgical hormone therapy was performed. The tissue expander was replaced by a definitive prosthesis McGhan $445 \mathrm{~g}$ (Natrelle 410, Allergan ${ }^{\circledR}$, Inc., Irvine, Calif; Mentor ${ }^{\circledR}$, Breast Implants, Santa Barbara, CA, USA) in June 2000.

During the medical examination at first aid unit, left breast deformity was noted and the patient was referred to our plastic surgery unit. The patient showed a mammographic ultrasound exam from November 2017, which reported the presence of a voluminous seroma of $1500 \mathrm{ml}$ and a severe prosthetic capsule contraction. The patient told that the cause of this examination was a slow swelling and consequent increase in left breast volume, which caused discomfort without pain. Our clinical examination showed an enlarged volume of the left breast and increased tension and slight inflammation of the overlying skin. Moreover, implant profile was not palpable and empty axilla for prior lymphadenectomy was evident. Given the clinical condition, high-resolution CT scan and MRI without contrast were carried out. High-resolution CT reported the presence of a voluminous liquid collection, capsular contraction, and prosthetic rupture. MRI without contrast increased the suspect of intra- and extra-capsular implant rupture and an associated peri-prosthetic fluid share (Figs. 1, 2, and 3). Moreover, MRI data evidenced an intra-capsular mass with an area of costal cartilage erosion that led us to consider ALCL in differential diagnosis (Fig. 4).

At the admission, patient's routine laboratory test results were within normal limits (except for creatinine) and she underwent surgery. Surgical left breast dissection was performed through the previous equatorial scar. Voluminous hematoma of $1500 \mathrm{ml}$ was drained and peri-capsular vessels were cauterized. Peri-prosthetic fluid was sent for pathology examination for a differential diagnosis with anaplastic large cell lymphoma (ALCL). No neoplastic cells were found and serological tests were negative for ALCL.

Despite the imaging data, the removed breast implant was found intact. The capsule was very adherent to the surrounding tissues: pectoralis major muscle band, subcutaneous fat,

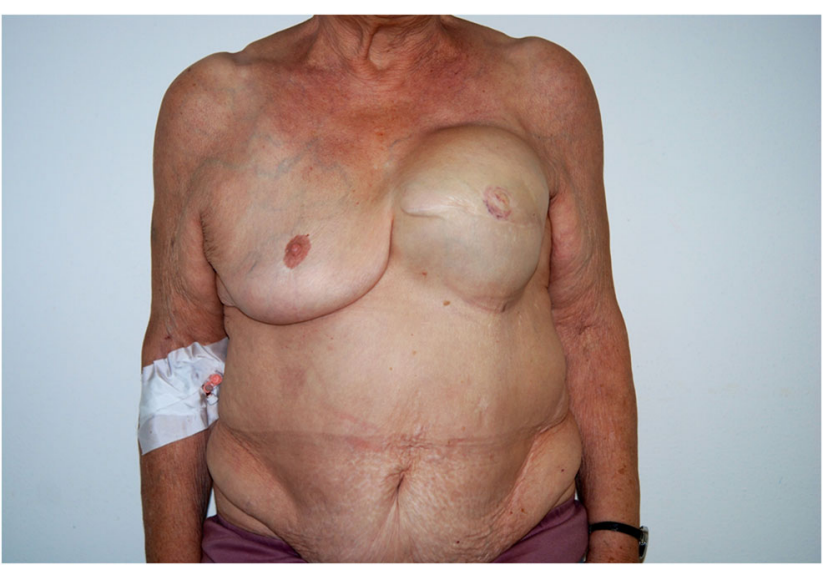

Fig. 1 This 83-year-old woman presented 19 years after left breast reconstruction with McGhan $445 \mathrm{~g}$ implants. Note the significant enlargement of the right breast

thoracic wall, and ribs. We noted a strange black, exophytic intra-pocket formation close to thoracic wall with soft consistency. After a complex superior pole capsulectomy, we proceeded with difficult partial inferior pole capsulectomy. Capsule was interrupted beneath the exophytic formation. We sent capsule, shaved black formation, and a fragment of wound bottom (adherent to the rib and corresponding to the back of black formation) for pathology examination. An accurate hemostasis, wash with $\mathrm{H}_{2} \mathrm{O}_{2}$ and saline solution, and sutures were performed. Complete healing was reached within 3 months and no complication occurred. The patient refused any further breast reconstruction surgeries.

Pathology results showed a dense hyaline fibrous capsule without neoplastic cells. Hemosiderin pigment accumulation and specific inflammatory cells were found in the black formation, which was described as fibrous tissue with hemosiderin pigment. The fragment of wound bottom showed rearrangement phenomena and necrosis areas of the superficial rib cartilage.

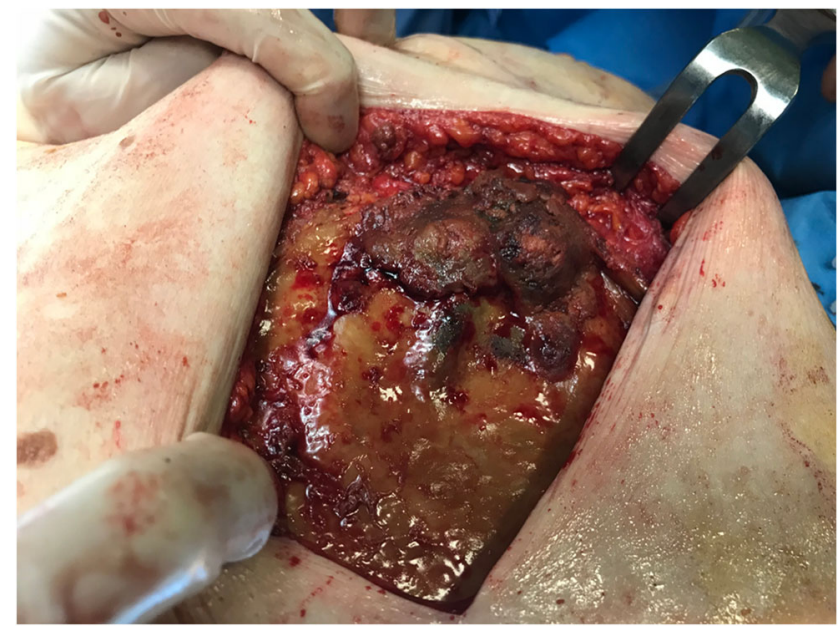

Fig. 2 and 3 Intraoperative situation, before and after removing periprosthetic capsule with necrotic area 


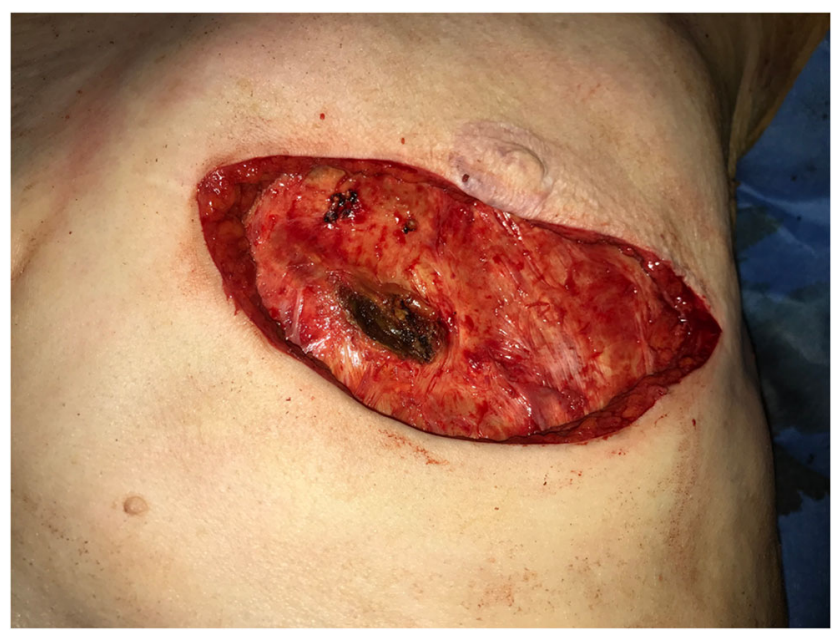

Fig. 4 MRI image demonstrating an intra-capsular area of costal cartilage erosion

\section{Discussion}

A systematic literature review concerning late hematoma cases was carried out. Late breast hematoma occurrences were studied analyzing their etiology and differential diagnosis. Searching on PubMed for "late breast hematoma", "delayed complications in breast surgery", and "Anaplastic Large Cell Lymphoma (ALCL)", 30 case reports regarding late hematoma were identified. Breast implant was inserted for esthetic purpose in 18 studies and for breast reconstruction in 12 reports. The average age for patients that underwent esthetic surgery was 41.65 years and 51.1 years for patients that underwent reconstructive surgery. Late hematoma onset varied from 4 months to 41 years after surgery. Several aetiologies were described and mechanical friction between the textured surface of the prosthesis and the high vascular capsule with a consequent capsule microfractures being the most common. Alike, various surgical treatments were explained, and breast implant removal with capsulectomy was the most frequent. Post-surgical outcomes were regular for most of patients, and only five cases reported complications or hematoma recurrences. These results are resumed in Table 1.

Since the first case of BIA-ALCL reported by Keech and Creech J [33], .the awareness of this rare pathology increased, and nowadays, its estimated incidence is 2.03 per 1 million person years, while its prevalence is estimated to be 1 per 30,000 women with breast implants [34]. In 2016, the World Health Organization (WHO) provisionally classified BIAALCL as a distinct lymphoma with disease-specific surgical treatment recommendations, [35] and in 2018, the FDA updated a safety communication in which a possible association between anaplastic large cell lymphoma (ALCL) and breast implants is showed. [36]. Reported cases to date worldwide are little more than 400, [37] and for its rarity, absolute risk remains low, even if the odds ratio for ALCL associated with breast implants is reportedly 18.2 [38]. Every spontaneous periprosthetic breast seroma not related to infection or trauma and occurring more than 1 year after surgery should be considered suspicious for BIA-ALCL [39]. BIA-ALCL has been estimated to occur in $9-13 \%$ of delayed seroma presentations [40] and it appears as a rapid onset of a spontaneous fluid collection (60-90\%) or capsular mass (10-40\%) at an average of 8 to 10 years after implantation [41].

BIA-ALCL must be distinguished from other, more frequent, periprosthetic liquid masses as seroma or hematoma. Late seroma is defined as a serous accumulation of periprosthetic exudate or effusion within the implant capsule, which appears at least 12 months after the implantation. It is a rare entity with an incidence of $0.88-1.84 \%$, while earlier seroma represents a more common complication [42-44].

Peri-prosthetic hematoma that occurs in the early postoperative period (first 3 days usually) presents an incidence of 2 $10.3 \%[15,45]$. Inadequate hemostasis, trauma, or coagulopathy represent the possible aetiologies.

Meanwhile, peri-prosthetic late hematomas that occur more than 6 months after surgery are considered rare complication with causes that remain often unknown [21]. The longest continuous breast implantation followed by explantation due to late hematoma was reported in 2007 by Nahabedian [5], where the prosthesis removal was performed 41 years after its positioning.

In the $76.9 \%$ of cases, it occurs in breasts with implants inserted for esthetic reasons [28] and ultrasonography and MRI appear to be useful tools for diagnosis, even if they do not distinguish late hematomas from implant ruptures easily and can give false results $[19,25,46]$. Chronic inflammation and erosion or corticosteroid therapies can damage pericapsular arteries and lead to late capsular hematoma [17]. Traumas are considered an another factor that can bring to late hematoma formation $[18,26]$.

In 1979, Georgiade et al [12] was the first to report a case of late hematoma in breast implant. This one was due to large use of corticosteroid that leads to erosion of a capsular artery and consequent bleeding. After this report, several authors described various physiopathologic events related to late hematomas in breasts with implants. Bleeding secondary to contracted capsular microfractures [47] was reported as cause of bilateral late hematoma in 1992 by Marques et al [13] and in 1995 by Cederna [14]. In 2003, the first case of late hematoma in association with tissue expander (Becker implant) was reported by Goyal et al., [20] who considered infective etiology, recurrent cancer, or implant rupture as differential diagnosis to investigate. In 2004, Brikman et al. [21] described a late hematoma 9 years after breast augmentation related to highly vascular inflammatory response created by polyurethane-coated implant, while Viega et al. [22] linked the development of a late hematoma to friction forces between textured prosthesis surface and surrounding tissues in only 


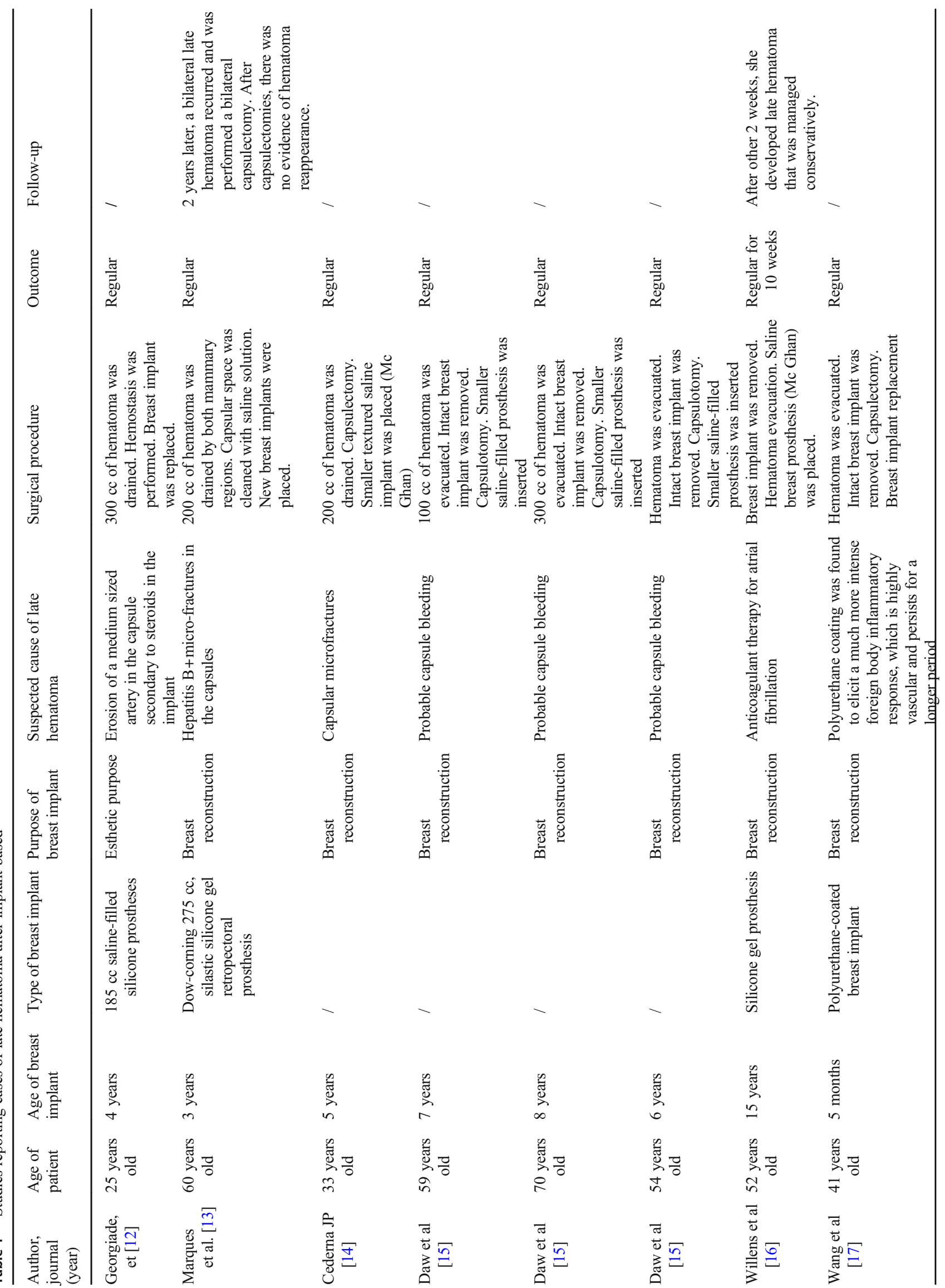




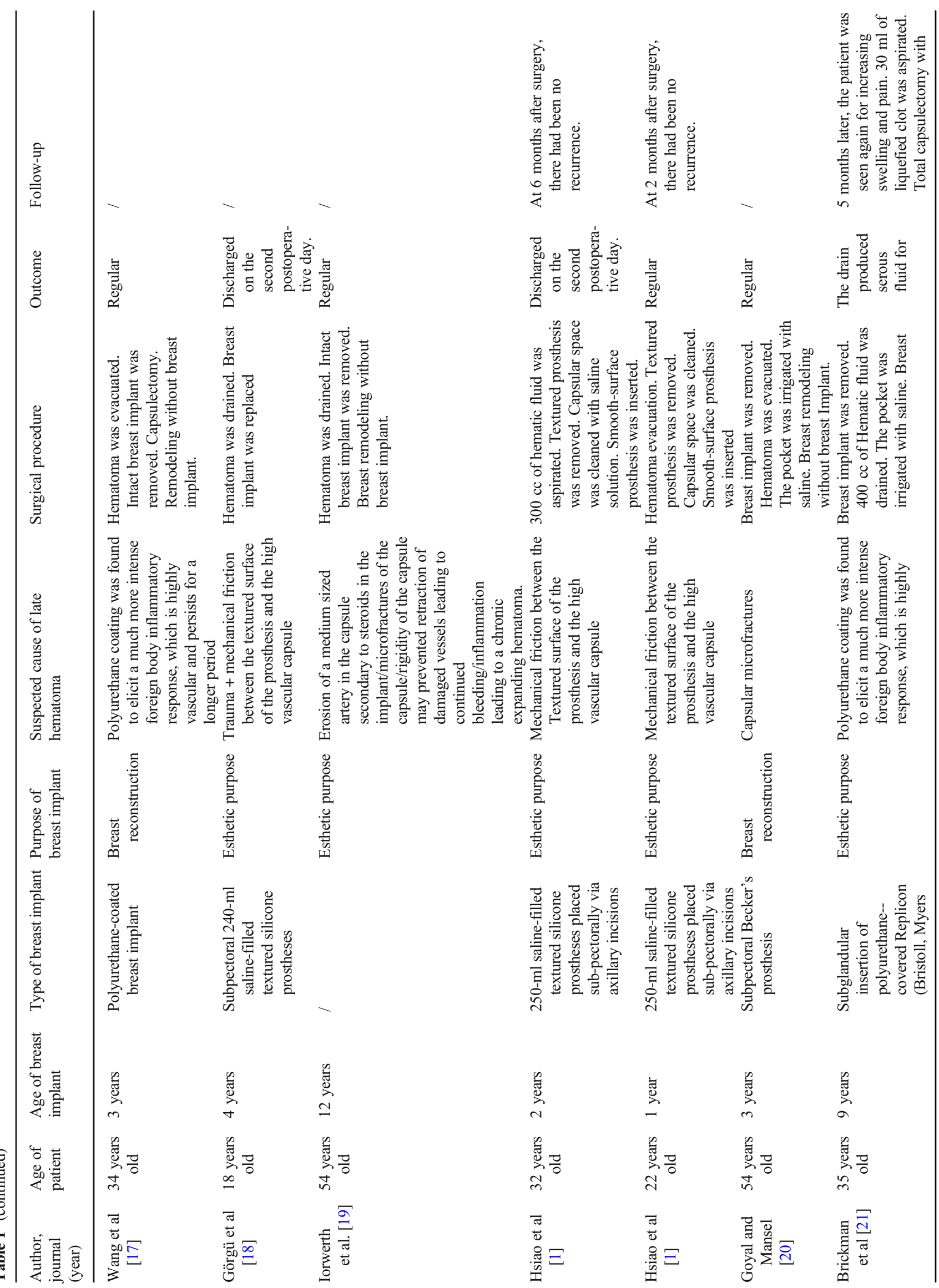




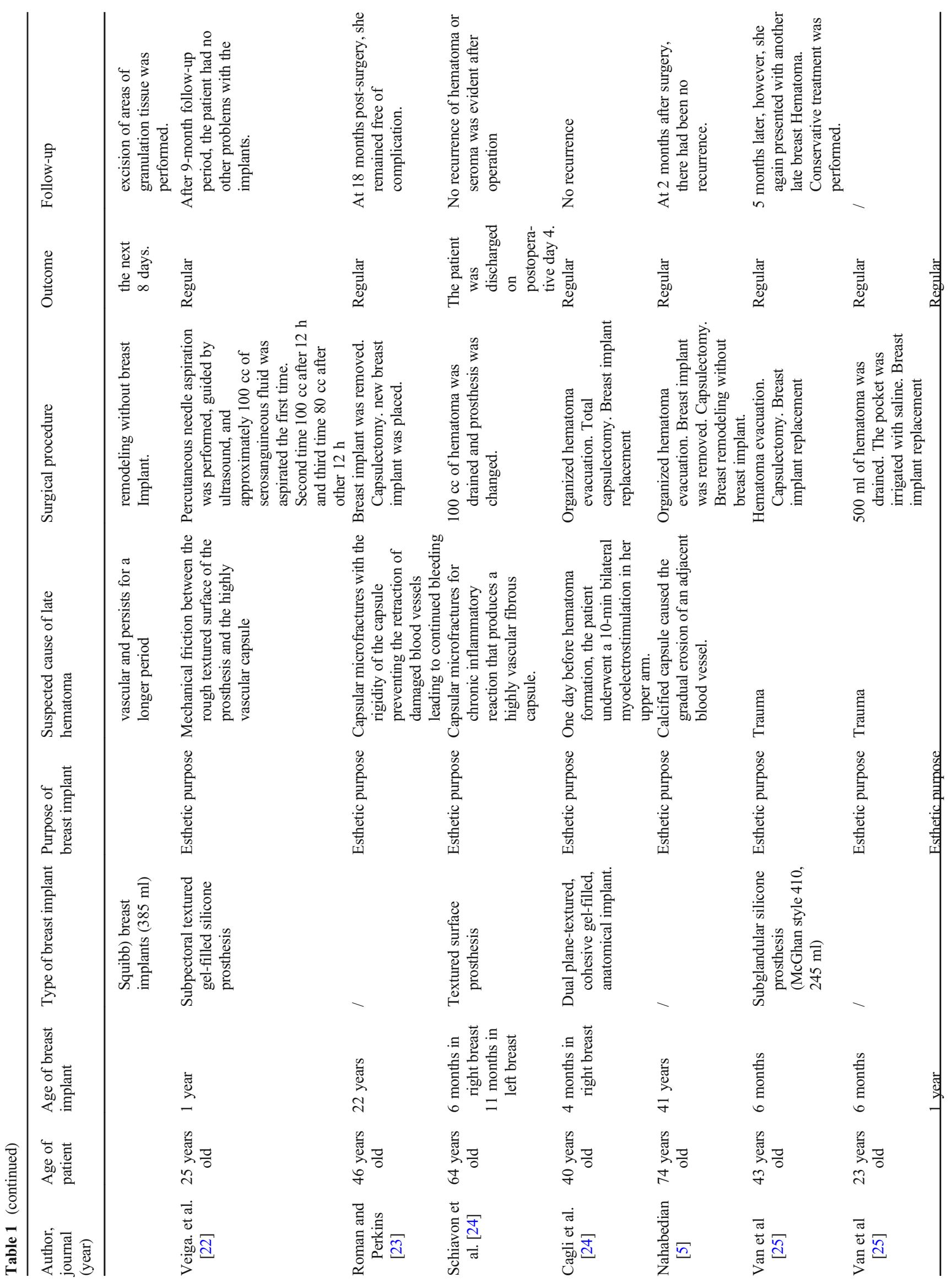




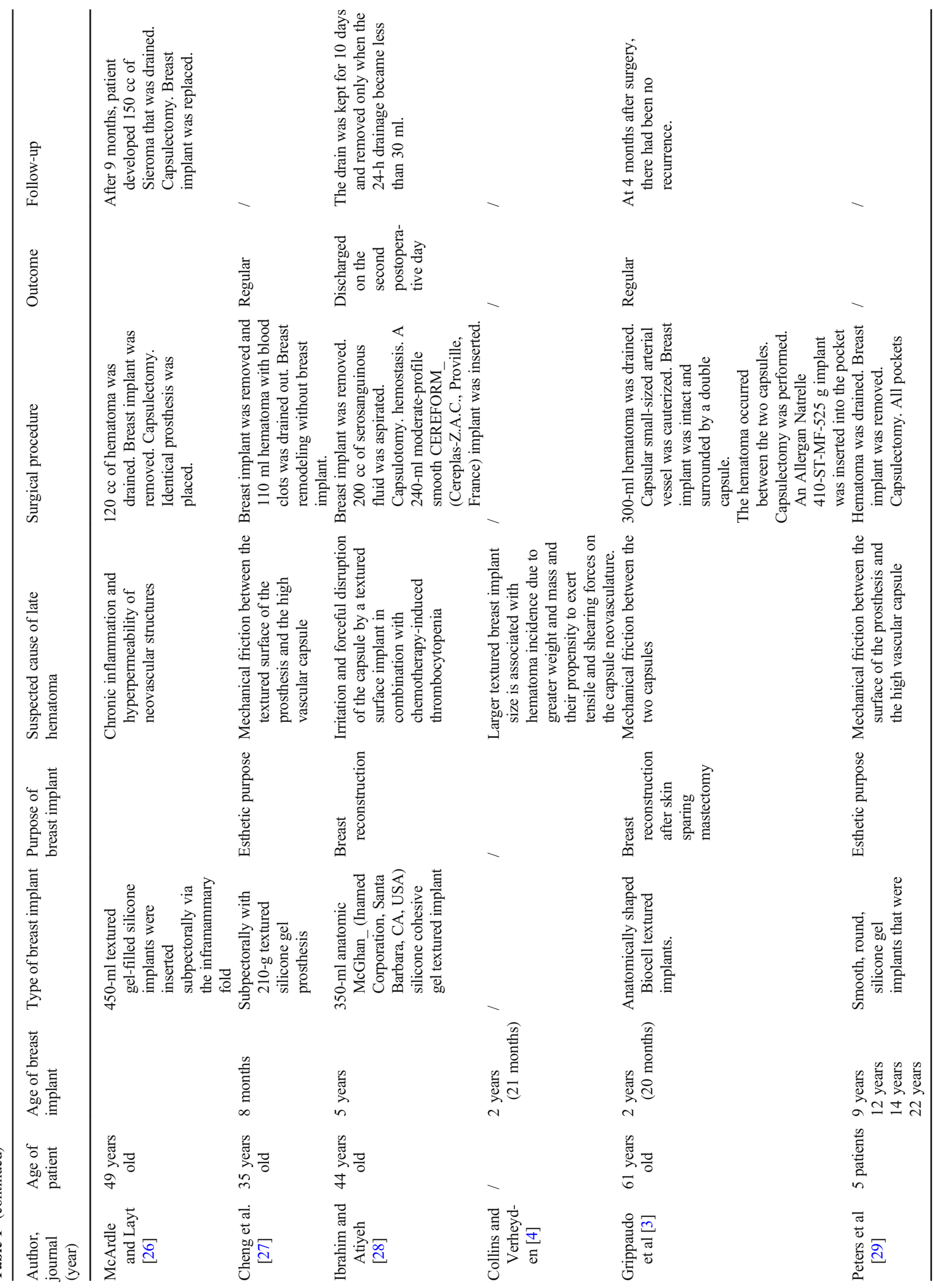




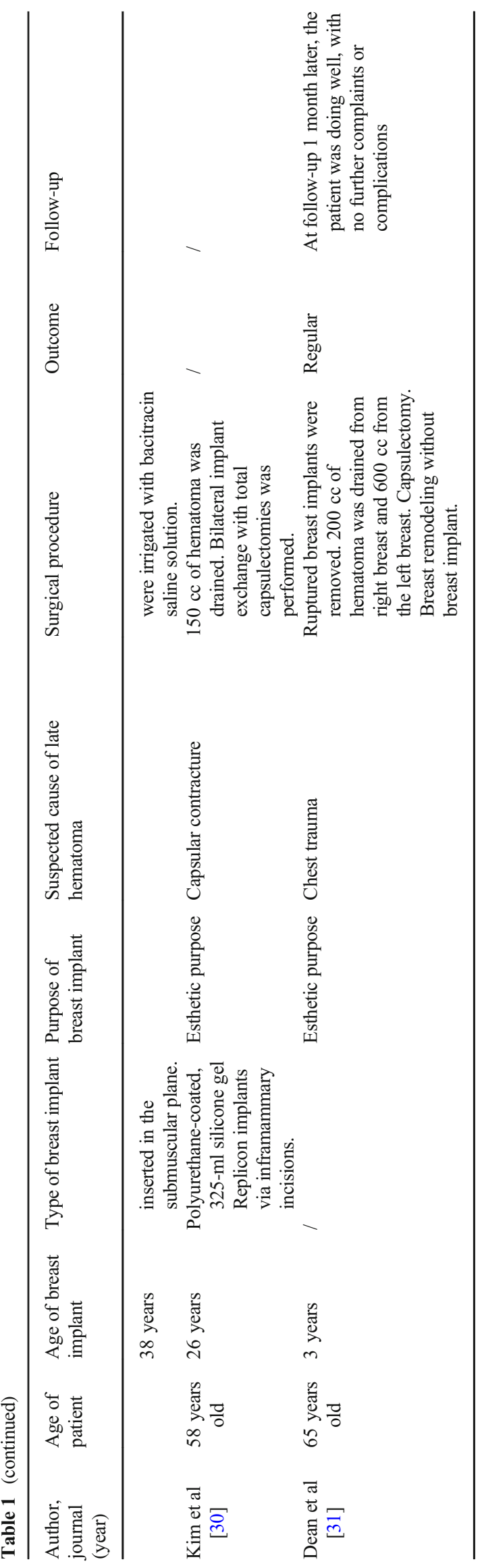

1 year after sub-glandular breast augmentation. In 2011, Ibrahim et al. [29] reported an another late hematoma case due to a bleeding disorder. The risk of late hematoma in anticoagulated patients with breast implants was previously described by Willens et al. [16] in 1996. Peters et al. [30] described a series of five cases of late hematomas that occurred from 9 to 38 years after breast augmentation surgeries. The authors portray those cases like chronic expanding hematomas [48] as they found multiple areas of recent and older hemorrhage within the structure of the capsules and on their surface. This comparison of late breast hematomas with chronic subdural hematomas was described by Roman [23] in 2005 even. In the past year, 2018, two cases of late hematoma were reported: Kim et al. [31] explained its development as a consequence of severe capsular contracture, while Dean et al. [32] described a case of silicone extravasation that may have led to chronic lymphocytic granulomatous reaction and a consequent recurrent acute-on-chronic hematoma.

Grippaudo et al. [3] in 2013 reported a singular case of late hematoma developed 2 years after breast surgery, due to mechanical friction in the space between the two layers of a double capsule. In the same article, a review of the literature is displayed and several cases of late hematomas are described. Late hematoma development between the two layers of a double capsule was also reported by Cagli et al. [25] in 2007. In this paper, the hematoma developed 4 months after an augmentation mammoplasty. Its physiopathologic cause was referable to a 10-min bilateral myoelectrostimulation in patient's upper arms, even if none of the electrodes was positioned on the pectoralis muscles.

Clear etiology of late hematoma is not always identified. Schiavon et al. [24] report an example of unknown etiology of late hematoma, showing a case that presented as a recurrent late complication, even. No causative factor was found also in the original case described by McArdle et al., [27] in which the patient presented late hematoma followed by late seroma 9 months after.

We would like to show the case that came to our unit, which appears to depend on original physiopathologic causes not described before. Our patient did not have painful swelling and there was not a triggering event. Differential diagnosis with ALCL was carried out with pathologic exam that did not find neoplastic cells. Based on macroscopic and pathologic exam evidences, we suggest that the implant applied a constant and continuous pressure on soft surrounding tissues. This force may have eroded tissues of thoracic wall until intercostal vessel damage and it caused bleeding with consequent late hematoma and the black formation that was identified as a necrosis area.

The first case reported by Georgiade et al. [12] is the only one in which a precise source of active bleeding in late breast hematoma was described. We show the second case in which 
the source of bleeding is identified and an original pathophysiology is suspected.

\section{Conclusions}

In the last years, ALCL has elicited much interest in scientific society as one of the most rare and important breast implantrelated complications. The ALCL phenomenon is widely discussed in many scientific journals [49] and may mislead surgeons. In every clinical case, physicians have to evaluate variables and differential diagnosis is led by accurate clinical examination, imaging data, and laboratory tests. In our case, late hematoma diagnosis was validated by surgery and laboratory tests because imaging data were not enough.

To date, peri-prosthetic late hematomas are considered a rare complication. Their pathophysiology is hard to explain and several authors reported in literature various possible aetiologies. In this specific report, we suppose that constant and continuous prosthesis's pressure on soft surrounding tissues, associated to high blood pressure, may have involved tissues of thoracic wall until causing rupture of a small costal vessel, producing a late bleeding with consequent hematoma. However, other reports are useful to establish frequency, etiology, and clinical manifestations of this rare complication that has presented a noticeable increase in recent years. Plastic surgeons have to know this rare condition and apply proper management when it is necessary.

Funding Open access funding provided by Università degli Studi di Roma La Sapienza within the CRUI-CARE Agreement.

\section{Compliance with ethical standards}

Conflict of interest Fioramonti P, Lovero S, Kaciulyte J, Ribuffo D, and Frattaroli JM declare that they have no conflict of interest.

Ethics approval All procedures performed in studies involving human participants were in accordance with the ethical standards of the institutional and/or national research committee and with the 1964 Helsinki Declaration and its later amendments or comparable ethical standards. This is a case report and literature review. For this kind of studies, approval from an ethics committee is not required.

Informed consent Informed consent was obtained from the patient.

Patient consent Patient signed informed consent regarding publishing her data and photographs. The patient has consented to the submission of the case report to the journal.

Open Access This article is licensed under a Creative Commons Attribution 4.0 International License, which permits use, sharing, adaptation, distribution and reproduction in any medium or format, as long as you give appropriate credit to the original author(s) and the source, provide a link to the Creative Commons licence, and indicate if changes were made. The images or other third party material in this article are included in the article's Creative Commons licence, unless indicated otherwise in a credit line to the material. If material is not included in the article's Creative Commons licence and your intended use is not permitted by statutory regulation or exceeds the permitted use, you will need to obtain permission directly from the copyright holder. To view a copy of this licence, visit http://creativecommons.org/licenses/by/4.0/.

\section{References}

1. Hsiao HT, Tung KT, Lin CS (2002) Late hematoma after aesthetic breast augmentation with saline filled, textured saline implants. Aesthet Plast Surg 26(5):368-371

2. Marcasciano M, Frattaroli J, Mori FLR, Lo Torto F, Fioramonti P, Cavalieri E, Kaciulyte J, Greco M, Casella D, Ribuffo D (2019) The new trend of pre-pectoral breast reconstruction: an objective evaluation of the quality of online information for patients undergoing breast reconstruction. Aesthet Plast Surg 43(3):593-599

3. Grippaudo FR, Renzi L, Costantino B, Longo B, Santanelli F (2013) Late unilateral hematoma after breast reconstruction with implants: Case report and literature review. Aesthet Surg J 33(6): 830-834

4. Collins JB, Verheyden CN (2012) Incidence of breast hematoma after placement of breast prosthesis. Plast Reconstr Surg 129:413e$420 \mathrm{e}$

5. Nahabedian MY (2007) Explantation of 41-year-old implants following primary breast augmentation. Ann Plast Surg 58(1):91-94

6. Collett DJ, Rakhorst H, Lennox P, Magnusson M, Cooter R, Deva AK (2019) Current risk estimate of breast implant-associated anaplastic large cell lymphoma in textured breast implants. Plast Reconstr Surg 143(3S A Review of Breast Implant-Associated Anaplastic Large Cell Lymphoma):30S-40S

7. Rupani A, Frame JD, Kamel D (2015) Lymphomas associated with breast implants: a review of the literature. Aesthet Surg J 35:533544

8. Brody GS, Deapen D, Taylor CR et al (2015) Anaplastic large cell Lymphoma occuring in women with breast implants: analysis of 173 cases. Plast Reconstr Surg 135(3):695-705. https://doi.org/10. 1097/PRS.0000000000001033

9. Doren EL, Miranda RN, Selber JC et al (2017) U.S. epidemiology of breast implant-associated anaplastic large cell lymphoma. Plast Reconstr Surg 139(5):1042-1050

10. Kricheldorff J, Fallenberg EM, Solbach C, Gerber-Schäfer C, Rancsó C, von Fritschen U (2018) Breast implant-associated lymphoma the diagnosis and treatment of a new disease entity. Dtsch Arztebl Int 115:628-635

11. Taylor CR, Siddiqi IN, Brody GS (2013) Anaplastic large cell lymphoma occurring in association with breast implants: review of pathologic and immunohistochemical features in 103 cases. Appl Immunohistochem Mol Morphol 21:13-20

12. Georgiade NG, Serafin D, Barwick W (1979) Late development of hematoma around a breast implant, necessitating removal. Plast Reconstr Surg 64:708-710

13. Marques AF, Brenda E, Saldiva PH, Andrews JM (1992) Capsular hematoma as a late complication in breast reconstruction with silicone gel prostheses. Plast Reconstr Surg 89(3):543-545

14. Cederna JP (1995) Hematoma as a late complication in breast reconstruction with silicone gel prostheses. Plast Reconstr Surg 96(1): 235-236

15. Daw JL, Lewis VL, Smith JW (1996) Chronic expanding hematoma within a periprosthetic breast capsula. Plast Reconstr Surg 97(7):1469-1472 
16. Willens HJ, Wald H, Kessler KM (1996) Late intracapsular hemorrhage in an anticoagulated patient with a breast implant. Chest. 110(1):304-305

17. Wang BH, Chang BW, Sargeant R, Manson PN (1998) Late capsular hematoma after breast reconstruction with polyurethanecovered implants. Plast Reconstr Surg 102(2):450-452

18. Görgü M, Aslan G, Tuncel A, Erdogan B (1999) Late and longstanding capsular hematoma after aesthetic breast augmentation with a saline-filled silicone prosthesis: A case report. Aesthet Plast Surg 23(6):443-444

19. Iorwerth A, Cochrane R, Webster DJ (2000) Chronic haematoma as a late complication of cosmetic breast augmentation. Breast. 9(3): $158-160$

20. Goyal A, Mansel RE (2003) Haematoma as a late complication after breast reconstruction with implant. Br J Plast Surg 56(2): 189-191

21. Brickman M, Parsa NN, Parsa FD (2004) Late hematoma after breast implantation. Aesthet Plast Surg 28(2):80-82

22. Veiga DF, Filho JV, Schaider CS et al (2005) Late hematoma after aesthetic breast augmentation with textured silicone prosthesis: a case report. Aesthet Plast Surg 29:431-433

23. Roman S, Perkins D (2005) Progressive spontaneous unilateral enlargement of the breast twenty-two years after prosthetic breast augmentation. Br J Plast Surg 58(1):88-91

24. Schiavon M, Fraccalanza E, Baraziol R (2005) Late recurrent capsular hematoma after augmentation mammaplasty: case report. Aesthet Plast Surg 29(1):10-12

25. Cagli B, Vulcano E, Marangi GF, Cogliandro A, Persichetti P (2007) Late hematoma after augmentation mammaplasty apparently due to myoelectrostimulation. Plast Reconstr Surg 119(1):439440

26. Van Rijssen AL, Wilmink H, van Wingerden JJ, van der Lei B (2008) Amorous squeezing of the augmented breast may result in late capsular hematoma formation: A report of two cases (and a review of English-language literature on late hematoma formation in the augmented breast). Ann Plast Surg 60(4):375-378

27. McArdle B, Layt C (2009) A case of late unilateral hematoma and subsequent late seroma of the breast after bilateral breast augmentation. Aesthet Plast Surg 33(4):669-670

28. Cheng NX, Chen B, Li Q, Wu DH, Zhu L, Zhang XM, Chen YL (2011) Late haematoma and seroma in patients with silicone mammary prosthesis: Our reports and literature review. J Plast Reconstr Aesthet Surg 64(7):e185-e186

29. Ibrahim AE, Atiyeh BS (2011) Management of delayed capsular hematoma after breast reconstruction. Aesthet Plast Surg 35:923927

30. Peters W, Fornasier V, Howarth D (2014) Late unilateral hematoma after breast augmentation. Plast Surg 22(1):18-21

31. Kim L, Castel N, Parsa FD (2018) Case of late hematoma after breast augmentation. Arch Plast Surg 45(2):177-179

32. Dean RA, Glener AD, Thomas AB, Glener SR, Kurtovic S, Erdmann D (2018) Silicone migration and late hematoma following silicone implant rupture: case report and literature review. Plast Reconstr Surg Glob Open 6(8):e1849

33. Keech A Jr, Creech BJ (1997) Anaplastic T-cell lymphoma in proximity to a saline-filled breast implant. Plast Reconstr Surg 100(2): 554-555

34. Berlin E, Singh K, Mills C, Shapira I, Bakst RL, Chadha M (2018) Breast implant-associated anaplastic large cell lymphoma: case report and review of the literature. Case Rep Hematol 2018:2414278

35. Clemens MW, Nava MB, Rocco N, Miranda RN (2017) Understanding rare adverse sequelae of breast implants: anaplastic large-cell lymphoma, late seromas, and double capsules. Gland Surg 6(2):169-184

36. FDA. (2019) Regulatory history of breast implants in the U.S. history of breast implant regulation. https://www.fda.gov/ MedicalDevices/ProductsandMedicalProcedures/ ImplantsandProsthetics/BreastImplants/ucm239995.htm. Accessed March 28, 2019

37. Beydoun AS, Ovalle F Jr, Brannock K, Gobble RM (2019) A case report of a breast implant-associated plasmacytoma and literature review of non-ALCL breast implant-associated neoplasms. Aesthet Surg J 39(7):NP234-NP239

38. Xu J, Wei S (2014) Breast implant-associated anaplastic large cell lymphoma: review of a distinct clinicopathologic entity. Arch Pathol Lab Med 138(6):842-846

39. Clemens MW, Brody GS, Mahabir RC, Miranda RN (2018) How to diagnose and treat breast implant-associated anaplastic large cell lymphoma. Plast Reconstr Surg 141(4):586e-599e

40. Di Napoli A, Pepe G, Giarnieri E et al (2017) Cytological diagnostic features of late breast implant seromas: from reactive to anaplastic large cell lymphoma. PLoS One 12:e181097

41. Clemens MW, Medeiros LJ, Butler CE et al (2016) Complete surgical excision is essential for the management of patients with breast implant-associated anaplastic large-cell lymphoma. J Clin Oncol 34:160-168

42. Kästner S, Paprottka FJ, Gonser P, López MV, Kaye KO (2018) Recurrent 8-year ongoing unilateral breast seroma formation after PIP implant removal-a case report and review of the literature. Surg J (N Y) 4(1):e46-e51

43. Marcasciano Md M, Kaciulyte J, Gentilucci M, Barellini L, Ribuffo D, Casella D (2018) Skin-reduction breast reconstructions with prepectoral implant covered by a combined dermal flap and titanium-coated polypropylene mesh. J Plast Reconstr Aesthet Surg 71(8):1123-1128

44. Marcasciano M, Kaciulyte J, Marcasciano F, Lo Torto F, Ribuffo D, Casella D (2019) No drain, no gain: simultaneous seroma drainage and tissue expansion in pre-pectoral tissue expander-based breast reconstruction. Aesthet Plast Surg 43(4):1118-1119

45. Lo Torto F, Cigna E, Kaciulyte J, Casella D, Marcasciano M, Ribuffo D (2017) National Breast reconstruction utilization in the setting of postmastectomy radiotherapy: two-stage implant-based breast reconstruction. J Reconstr Microsurg 33(5):e3

46. Marcasciano M, Conversi A, Kaciulyte J, Dessy LA (2017) RE: Prosthetic breast implant rupture: imaging-pictorial essay: full cooperation between surgeon and radiologist: "the best of both worlds". Aesthet Plast Surg 41(6):1478-1480

47. Lo Torto F, Vaia N, Casella D, Marcasciano M, Cigna E, Ribuffo D (2018) Delaying implant-based mammary reconstruction after radiotherapy does not decrease capsular contracture: An in vitro study. J Plast Reconstr Aesthet Surg 71(1):28-29

48. Labadie EL, Glover D (1976) Physiopathogenesis of subdural hematomas: part 1. Histological and biochemical comparisons of subcutaneous hematoma in rats with subdural hematoma in man. $\mathrm{J}$ Neurosurg 45(4):382-392

49. McCarthy CM, Loyo-Berríos N, Qureshi AA, Mullen E, Gordillo G, Pusic AL, Ashar BS, Sommers K, Clemens MW (2019) Patient registry and outcomes for breast implants and anaplastic large cell lymphoma etiology and epidemiology (PROFILE): initial report of findings, 2012-2018. Plast Reconstr Surg 143:65S-73S

Publisher's note Springer Nature remains neutral with regard to jurisdictional claims in published maps and institutional affiliations. 